\title{
2D and 3D texture analysis to differentiate brain metastases on MR images: proceed
}

\section{with caution}

\author{
Monika Béresova ${ }^{1,4}$, Andrés Larroza $^{2}$, Estanislao Arana $^{3}$, \\ József Varga ${ }^{4}$, Lászlo Balkay ${ }^{4}$, David Moratal ${ }^{5}$
}

${ }^{1}$ Div. of Radiology, Department of Medical Imaging, Faculty of Medicine, University of Debrecen, Debrecen, Hungary

${ }^{2}$ Department of Medicine, Universitat de València, Valencia, Spain

${ }^{3}$ Department of Radiology, Fundación Instituto Valenciano de Oncología, Valencia, Spain

${ }^{4}$ Div. of Nuclear Medicine, Department of Medical Imaging, Faculty of Medicine, University of Debrecen, Debrecen, Hungary

${ }^{5}$ Center for Biomaterials and Tissue Engineering, Universitat Politècnica de València, Valencia, Spain

\section{Corresponding author:}

Monika Béresová, PhD student

e-mail: beres.monika@med.unideb.hu

Div. of Radiology, Department of Medical Imaging,

Faculty of Medicine, University of Debrecen, Hungary

4032 Debrecen, Nagyerdei krt. 98, Hungary

Tel.: (+36) 303951645 
Word count of abstract: 208

Word count of text: 5062

Number of figures: 6

Number of tables: 8

Number of references: 37 


\begin{abstract}
Object: To find structural differences between brain metastases of lung and breast cancer, computing their heterogeneity parameters by means of both $2 \mathrm{D}$ and $3 \mathrm{D}$ texture analysis (TA).
\end{abstract}

Materials and Methods: Patients with fifty-eight brain metastases from breast (26) and lung cancer (32) were examined by MR imaging. Brain lesions were manually delineated by $2 \mathrm{D}$ ROIs on the slices of contrast-enhanced T1-weighted (CET1) images, and local binary patterns (LBP) maps were created from each region. Histogram-based (minimum, maximum, mean, standard deviation and variance), and co-occurrence matrix-based (contrast, correlation, energy, entropy and homogeneity) 2D, weighted average of the 2D slices, and true 3D TA were obtained on the CET1 images and LBP maps.

Results: For LBP maps and 2D TA contrast, correlation, energy and homogeneity were identified as statistically different heterogeneity parameters (SDHPs) between lung and breast metastasis. The weighted 3D TA identified entropy as an additional SDHP. Only two texture indexes (TI) were significantly different with true 3D TA: entropy and energy. All these TIs discriminated between the two tumor types significantly by ROC analysis. For the CET1 images there was no SDHP at all by 3D TA.

Conclusion: Our results indicate that the used textural analysis methods may help with discriminating between brain metastases of different primary tumors.

Keywords: image processing, computer-assisted; texture analysis; Magnetic Resonance Imaging; brain neoplasms; metastasis; breast cancer; lung cancer 


\section{Introduction}

Brain metastases are the most common intracranial neoplasms in adults, and they occur in nearly $20-40 \%$ of metastatic cancer patients [1-2]. The incidence of brain metastases is increasing, which is believed to be due to the introduction of more sensitive diagnostic methods, improved systemic therapies leading to advances in extracranial control and survival, and the more frequent use of screening studies [3]. Eighty percent of brain metastases originate from lung, breast, melanoma, gastrointestinal tract adenocarcinomas, and renal cell carcinoma [4]. From among these, the brain metastases from lung and breast are the most common in clinical practice. [5] On contrast-enhanced MRI that is the imaging technique of choice for screening and initial staging, brain metastases are prominently wellcircumscribed, either homogeneous or show ring enhancement, and they are sometimes surrounded by vasogenic oedema [6-8].

Several physiological and morphological features of tumors reflect heterogeneity; for instance, the proliferative and angiogenic potential and expression of cell surface receptors, among others $[9,10]$. While the majority of tissue characterisation procedures by MR imaging [11] are not quantitative, a different kind of analytical methods, texture analysis, allows quantifying regions or lesions in the image [12], and seems to be very promising in the field of tumor diagnosis.

Several textural studies computed local heterogeneity parameters of the gray level cooccurrence matrix (GLCM) from MRI, PET and PET/MRI studies to investigate textural differences [13, 14]. GLCM is a gray-level spatial dependence matrix, consisting of values that show how often specific pairs of pixel value occur in a given spatial relationship in an image [12]. Recently the so-called large space conquest classification method was employed to investigate the textural parameters of brain MRI images, based on support vector machine, 
or grading machine learning schemes [15]. The extraction of texture information can rely on several techniques, among which the Local Binary Pattern (LBP) method is getting more attention lately, as it provides promising results for a bunch of different applications [16, 17]. LBP was first introduced by Ojala et al. to detect local binary patterns in circularly symmetric areas at a predefined number of neighbourhoods within a radius [18]. LBP image processing offers an excellent measure of the spatial structure of local image texture at the expense of contrast, the latter being also an important property of the lesion [19].

Differentiation of brain metastases is a common problem in MR imaging. Textural analysis could differentiate metastases from radiation necrosis after radiotherapy [15], or from primary brain tumors [20]. Previous attempts to non-invasively differentiate histological subsets of brain metastases by MR spectroscopy have been unsuccessful [21], but recently brain metastases of different types of lung cancer could be efficiently separated by TA [22].

In addition, there are at least two conceptually different texture analysis methods, the $2 \mathrm{D}$ and the 3D approaches. Mahmoud-Ghoneim et al showed that 3D method gives a better discrimination between necrosis and solid tumor as well as between edema and solid tumor [23]. Recently several other studies investigated the differences of the 2D and 3D TA, and stated that the $3 \mathrm{D}$ computation could provide more promising results $[24,25,26,27]$ based on trained classification algorithms.

The aim of our study was to investigate whether textural parameters computed from contrastenhanced T1-weighted MR images could be used to differentiate brain metastases of lung cancer from those of breast cancer based on 2D or 3D TA. 


\section{Materials and methods}

This retrospective, single-centre study was approved by the Institutional Review Board, and all subjects provided written informed consent. Patients with fifty-eight brain metastasis had been diagnosed between September 2014 and June 2015 were included. Twenty-six lesions were breast cancer origin (Luminal-B, 8; human epidermal growth factor-2 (HER-2), 9; triple negative breast cancer (TNBC), 9). Thirty-two lesions were lung cancer origin: thirteen of these subjects had small cell lung carcinoma (SCLC), while the rest were non-small cell lung carcinomas (NSCLC). Fourteen of the NSCLC group were adenocarcinomas, and five were squamous cell lung carcinomas. The patients harboured a total of 58 metastases (median volume $4458 \mathrm{~mm}^{3}$ and $2412 \mathrm{~mm}^{3}$, range $8.1-63603 \mathrm{~mm}^{3}$ and $143-27468 \mathrm{~mm}^{3}$ for the breast and the lung metastases, respectively).

All MRI examinations were performed using a 1.5 Tesla magnet with a multichannel phasedarray coil (Magnetom Symphony; Siemens Healthcare, Erlangen, Germany). The MRI protocol included T1-weighted axial images with gadolinium, and T2-weighted FLAIR axial images. Three-dimensional (3D) spoiled gradient recalled echo (SPGR) T1-weighted images of the whole brain were acquired without magnetization transfer, following intravenous administration into the antecubital vein of a single-dose of gadobenate dimeglumine $(0.1$ $\mathrm{mmol} / \mathrm{kg}$, MultiHance, Bracco; Milan, Italy) with a 6-min delay. SPGR parameters were $\mathrm{TE} / \mathrm{TR}=11 / 4.76 \mathrm{~ms}$, flip angle $=25$, and contrast-enhanced T1-weighted images were acquired with the following parameters: slice thickness $=1.5 \mathrm{~mm}$, pixel size $=1.3 \times 1.3 \mathrm{~mm}^{2}$, image size $=512 \times 512$

Elliptical low-pass filter was activated on every MRI sequence. This low-pass filter sets the corners of the k-space to zero, and thus can improve the SNR without substantially decreasing spatial resolution. [28] 


\section{Texture analysis in 2D}

Altogether 846 slices of 58 brain lesions were manually delineated by an expert radiologist (with 15 years' experience in neuroradiology). 2D binary masks were created slice-by-slice from the segmented volumes of every metastasis. To analyse heterogeneity, histogram-based (minimum [Min], maximum [Max], mean, standard deviation [SD], variance, SD/mean and median), and co-occurrence matrix features were computed in Matlab version 2014b (The MathWorks Inc., Natick, MA). Co-occurrence matrices were calculated at one-pixel distance from the segmented lesions, after scaling (normalizing) to 64 gray levels. Then the contrast, correlation, energy, homogeneity and entropy features were calculated in four directions $(0$, 45, 90 and $135^{\circ}$ ). Each feature was then averaged over the four matrices to achieve rotational invariance. Formulas for computing the features are presented in Table 1. We calculated all the features mentioned above from both the CET1 images and LBP maps (Figure 1).

The LBP map determines the relationships between each pixel and its neighbouring pixels encoding this relation into a new advanced map, in which the pixel values are confined to the range $0-255$. This allows detection of patterns or features, while it is immune to contrast changes [16]. Parameters of the LBP were set to $p=8$ and $r=1$, where $p$ is the number of neighbour pixels in the circular area of radius $r$ around a certain pixel. We describe briefly the computational steps. The image was divided into $3 \times 3$ pixel blocks, and the pixels in a block were thresholded using its centre pixel value setting the eight different pixels to "0" or " 1 ". After this thresholding LBP value for the central pixel was calculated by multiplying the threshold values with $2^{\mathrm{p}}$ given by the $p$ th pixels ( $\left.\mathrm{p}=0-7\right)$, and summing up the results. Because the neighbourhood consists of 8 pixels, a total of 256 different LBP levels can be obtained depending on the relation between the gray values of the centre and the neighbourhood pixels $[18]$. 
In computing 2D co-occurrence matrices for a given ROI, the outside pixels were removed using the method described by L. Zhenjiang et al. [29], and all heterogeneity parameters were calculated within the ROIs.

Four hundred and fifteen and 431 ROIs within metastases from breast and lung cancer, respectively, were studied. ROIs were categorized into four subgroups according to the following size ranges: $0-1935,1936-3845,3846-7700$ and $7701-11540 \mathrm{~mm}^{2}$, as textural features may depend on ROI size [30].

Texture analysis in 3D

First, a weighted 3D (2D converted to 3D) TI was calculated based on the 2D TIs and taking into account the different 2D ROI sizes at a given tumor volume. We computed the weighted average of the 2D TIs of a tumor VOI with the numbers of ROI pixels as weights. Second, we computed the true 3D texture indexes in Matlab, too. For both LBP and CET1 images we used the cooc3d.m function from the Matlab FileExchange website provided by Carl Philips [31]. The number of directions and the gray levels were 13 and 64, respectively. Then (as in 2D data analysis) the pixels outside the 3D binary masks were removed. Due to the smaller sample size (the number of metastatic groups were 26 and 32), the 3D TA ROIs into size subgroups. 


\section{Statistical analysis}

The Kolmogorov-Smirnov test was performed to check the normality of the distribution on CET1 images and LBP maps. For normally distributed data with similar SDs for both groups the 2-sample t-test was used, while for the rest the Mann-Whitney test was applied. During the $2 \mathrm{D}$ analysis the Bonferroni adjustment for multiple comparisons (12 features) was also applied by setting the threshold level to $\mathrm{p}<0.004\left(\mathrm{p}<1-0.95^{1 / 12}\right)$. To assess the diagnostic power of each TI, ROC (receiver characteristic curve) analysis was used.

Discriminant Function Analysis (DFA) was done separately for the histogram-based (mean, $\mathrm{SD}$, median, size) and co-occurrence matrix based (contrast, correlation, energy, entropy and homogeneity) parameters. The conditions of the DFA were checked using F-test (equality of group means) and Box's test (equality of covariance matrices). For cross validation, each case was classified by the functions derived from all other cases.

All statistical calculations were done using the SPSS package version 22 (IBM, Somers, NY).

\section{Results}

Texture analysis in 2D

The frequency distribution of ROI sizes, and the necrosis status are shown in Tables 2a and 2b. Our data demonstrated that metastatic enlargement in most cases showed necrotic lesions. Results of the Kolmogorov-Smirnov test $(\mathrm{p}<0.05)$ showed more non-normally (67) than normally distributed (29) parameters, as presented in Table 3. This table displays all of the 12 available features by size, depicting the selected statistical tests (Mann-Whitney or t-test).

A summary of the number of statistically different heterogeneity parameters is shown for each ROI size subgroup in Table 4. The details are provided in Tables 5 and 6. In general, textural 
analysis provided significant differences in more cases when calculated from the LBP maps (Table 6). Based on the analysis of CET1 images, there were no significant differences in the 12 parameters between breast and lung metastases in the smallest ROI size $1\left(0-1935 \mathrm{~mm}^{2}\right)$, (Table 5). Considering the histogram-based parameters, there were no statistically different ones in the smallest ROI size $\left(0-1935 \mathrm{~mm}^{2}\right)$ for the LBP maps either (Tables 5 and 6), while only two statistically different parameters were found in the largest ROI size (7701-11540 $\left.\mathrm{mm}^{2}\right)$.

Figure 2 shows boxplots of four texture parameters (contrast, correlation, energy and homogeneity) for all ROI sizes combined, based on the LBP maps. Only these features were significantly $(\mathrm{p}<0.004)$ different between the two metastatic groups. Figure 3 represents these parameters separately for each ROI size. Contrast values from lung metastases were lower than from breast metastases for all but one ROI size (size 2). On the other hand, correlation, energy and (except for the smallest ROIs) homogeneity values were greater for each size group in the case of lung metastases.

\section{Texture analysis in 3D}

For the 3D computation, just the two metastatic groups (26 from lung vs. 32 from breast) were compared. The results for the weighted and the true 3D TA on LBP images are presented in Table 7. In the case of the weighted 3D TI, the significantly different heterogeneity parameters (SDHPs) were the contrast, correlation, energy, homogeneity and entropy, which are almost the same parameters as in the $2 \mathrm{D}$ analysis. The exception is the entropy that was SDHP for three size groups of the four in the $2 \mathrm{D}$ evaluation. In contrast to this, the true 3D TA resulted only two statistically significant parameters on LBP images 
(without the Bonferroni correction), namely the energy and the entropy $(\mathrm{p}<0.05)$. In case of CET1 MR images we did not find any SDHPs.

In the next step, we performed ROC analysis to visualize the diagnostic value of the parameters of 3D TA. Figure $4 a, b$ show the five ROC curves for the weighted 3D TA of contrast, entropy, correlation, energy and homogeneity and they can be characterized not very large but similar AUC values, 0.661, 0.694, 0.714, 0.706 and 0.700, respectively. The Figure 5 presents the only 2 curves (entropy and energy) for the true 3D analysis, with the AUC of 0.683 and 0.669 . All these ROC curves showed statistically significant discrimination value $(\mathrm{p}<0.05)$

When checking the conditions of DFA, from among the 12 tests (3 data sets: 2D, 2d->3d, 3D; 2 matrix types: norm, LBP; 2 sets of variables: co-occurrence based, histogram-based), equality of covariance matrices was not met in 11 cases (Box's test); so Wilks' test could not be applied. The linear model could properly classify the origin of the metastases in $44-72 \%$ of the cases. For every data set, the highest percentage of correctly classified cases could be obtained from the LBP maps using the combination of co-occurrence-based parameters: 2D: $65.6 \%, 2 \mathrm{D}->3 \mathrm{D}: 63.8 \%, 3 \mathrm{D}: 72.4 \%$.

\section{Discussion}

This work presents application of 2D and 3D texture analysis for comparing brain metastases originating from breast and lung cancer by means of the analysis of both raw MR images, and parametric LBP maps. Our study found differences between the textural features of brain metastases of lung cancer from those of breast cancer based on LBP maps, but these differences essentially depended on the applied TA methods.

On the 2D analysis, LBP brain maps resulted in four significantly different co-occurrence matrix based parameters between the breast and the lung metastasis cases. These indexes were 
contrast, correlation, energy, and homogeneity, considering all sizes combined. As shown in

Figures 2-3, correlation, energy and homogeneity had higher values in lung metastasis cases, while the contrast values were significantly greater in the breast metastasis group on LBP maps. When comparing CET1 MR images to LBP maps, we found fewer number of SDHPs in 2D TA as presented in Tables 5 and 6 . In case of small lesions we could not find any significant textural differences between metastases from breast or lung cancer. This indicates reduced reliability of TA either when lesion sizes approach the spatial resolution of MRI, or near-surface slices are not representative of tumor histology. Interestingly, only two of the cooccurrence matrix features (contrast and correlation) were found to be statistically different for the larger ROI sizes.

Weighted 3D TA showed more SDHPs on LBP: contrast, correlation, energy, homogeneity and entropy. On the other hand, only 2 TIs were significantly different with true 3D TA, entropy and energy. Moreover, we obtained these results for the 3D methods without Bonferroni correction only; after applying the correction, we did not have any SDHPs. In addition, there were no SDHPs in CET1 MR images, performing either weighted or true 3D TA. These underline that the choice of the TA method to use is critical; the results and related inferences may vary according to the actual (2D or 3D) technique.

The energy and the entropy were significantly different parameters by all three methods. From among the textural features investigated, entropy (which reflects the unpredictability of the information content of an image) was previously found as a promising parameter in hepatic tumors [32]. It was considered to be one of the most representative prognostic textural parameters in several tumors studied by CT imaging $[32,33]$. Entropy was found a robust 
texture measure only accompanied with high gray-level run emphasis under different matrix

The lower performance of raw contrast-enhanced T1-weighted images compared to LBP maps may be related to image processing: LBP calculation consists of gray scale reduction and additional filtering operations, which dramatically reduce noise. As previously observed [35], the higher the image noise, the lower the reliability of any TA will be; which may explain why contrast-enhanced T1-weighted MRI images gave less SDHPs.

Nevertheless, in LBP maps the histogram-based features were only able to distinguish statistically different parameters in a maximum of two size ranges in 2D TA. An explanation for this unreliable behaviour maybe that the value of a histogram parameter strongly depends on the scale of the pixel values in the MR image, which is known to vary from one scan to another. In addition, we observed the largest variance of parameter values in the smallest ROI size $\left(0-1935 \mathrm{~mm}^{2}\right)$ for $2 \mathrm{D} \mathrm{TA}$, and, as a consequence, the number of SDHPs was the lowest (4) in this size group for both image types (LBP maps and contrast-enhanced T1-weighted MR images). Beyond the fact that the slices that are closer to the tumor surface are typically smaller, this may be explained by the fact that the acceptability of any TA is affected by the spatial resolution of a given imaging modality. For the case of MRI, Sikiö et al. recently showed that using T2-weighted 2D turbo spin echo sequence on 3T brain imaging, at least an area of $\sim 70 \mathrm{~mm}^{2}$ was necessary for size-independent texture feature calculations [36]. Similar statement can be found for PET, as it was shown [37] that the minimal tumor volume for reliable TA was about $45 \mathrm{~cm}^{3}$ (corresponding to a central ROI size of $\sim 1500 \mathrm{~mm}^{2}$ ), which is at least 10 times higher than the volumetric resolution.

This research has several limitations. First, our study includes low number of investigated textural features: we calculated only 5 GLCM and 7 histogram-based parameters. A second limitation is related to the variability of MRI contrast obtained in the T1 post-contrast images, 
which depends on several factors such as the injection time, site of injection, time between injection and imaging, and in addition the patient-specific kinetics of the contrast material. In our study we applied a single site-specific CET1 MRI protocol, with fixed 6-min delay. Another limitation was that we investigated only two of the most common types of brain metastasis.

\section{Conclusion}

We found several heterogeneity parameters showing differences between metastatic brain lesions of different primary tumors. The parameters calculated from the LBP maps appeared to be more sensitive to the origin of the metastases. Our results indicate that the value of texture indexes may depend on the applied (2D or 3D) techniques; the methods of calculation substantially influence their value to differentiate between the types of pathological lesions. In our study the most promising texture indices were entropy and energy, that showed significant difference between the tumor types in all three calculation techniques (2D, weighted average of slices and true 3D) on LBP images.

\section{Acknowledgements}

This work was supported in part by the Spanish Ministerio de Economía y Competitividad (MINECO) and FEDER funds under grant BFU2015-64380-C2-2-R, by the „Richter Gedeon Talentum Alapítvány" and by the Campus Hungary Mobility Program. Andrés Larroza was funded by the Spanish Ministerio de Educación, Cultura y Deporte (MECD) under grant FPU12/01140. The authors also thank to the continuous help of Dr. Joaquin Gavila from Fundación IVO. 


\title{
Authors' Contribution
}

\author{
Contribution \\ Author(s) \\ Protocol/project development: $\quad$ David Moratal, Estanislao Arana, Monika Béresová \\ Data collection or management: David Moratal, Estanislao Arana, László Balkay \\ Andrés Larroza, Monika Béresová \\ Data analysis: $\quad$ David Moratal, Estanislao Arana, Balkay László, József \\ Varga, Monika Béresová
}

\section{Compliance with Ethical Standards}

Conflict of Interest: The authors declare that they have no conflict of interest.

Ethical approval: All procedures performed in studies involving human participants were in accordance with the ethical standards of the institutional and/or national research committee and with the 1964 Helsinki declaration and its later amendments or comparable ethical standards.

Informed consent: All exams came from individuals who gave informed consent at admission for research and follow-up, in accordance with Institutional Board Review (IBR) approval.

\section{References}

1. Nayak L, Quant Lee E, Wen PY (2012) Epidemiology of Brain Metastases. Curr Oncol Rep 14(1): 48-54

2. Brastianos HC, Cahill DP, Brastianos PK (2015) Systemic therapy of brain metastases. Curr Neurol Neurosci Rep 15: 518

3. Lee EK, Lee EJ, Kim MS, Kim MS, Park H-J, Park NH, Park S, Lee YS (2012) Intracranial metastases: spectrum of MR imaging findings. Acta Radiol 53(10): $1173-1185$ 
4. Kumar V, Abbas AK, Aster JC (2014) Robbins and Cotran Pathologic basis of disease. 9th edn. Elsevier, Philadelphia

5. Bekaert L, Emery E, Levallet G, Lechapt-Zalcman E (2017) Histopathologic diagnosis of brain metastases: current trends in management and future considerations. Brain Tumor Pathol 34(1):8-19

6. Fink KR, Fink JR (2013) Imaging of brain metastases. Surg Neurol Int 4(Suppl 4): S209-219

7. Balériaux D, Colosimo C, Ruscalleda J et al. (2002) Diagnostic neuroradiology magnetic resonance imaging of metastatic disease to the brain with gadobenate dimeglumine. Neuroradiol 44(3): 191-203

8. Yuh WTC, Fisher DJ, Runge VM, Atlas SW, Harms SE, Maravilla KR, Mayr NA, Mollman JE, Price AC (1994) Phase III Multicenter Trial of high-dose Gadoteridol in MR evaluation of brain metastases. AJNR Am J Neuroradiol 15(6): 1037-1051

9. Marusyk A, Polyak K (2010) Tumor heterogeneity: Causes and consequences. Biochim Biophys Acta 1805(1): 105-117

10. Marusyk A, Almendro V, Polyak K (2012) Intra-tumour heterogeneity: a looking glass for cancer? Nat Rev Cancer 12(5): 323-334

11. Lerski RA, Smith MJ, Morley P, Barnett E, Mills PR, Watkinson G, MacSween RNM (1981) Discriminant analysis of ultrasonic texture data in diffuse alcoholic liver disease: 1. Fatty liver and cirrhosis. Ultrason Imaging 3(2): 164-172

12. Haralick RM (1979) Statistical and structural approach to textures, Proceedings of the IEEE 67(5): 786-804 
13. Ng TSC, Bading JR, Park R, Sohi H, Procissi D, Colcher D, Conti PS, Cherry SR, Raubitschek AA, Jacobs RE (2012) Quantitative, simultaneous PET/MRI for intratumoral imaging with an MRI-compatible PET scanner. J Nucl Med 53(7): 1102-1109

14. Asselin M-C, O 'connor JPB, Boellaard R, Thacker NA, Jackson A (2012) Quantifying heterogeneity in human tumours using MRI and PET. Eur J Cancer 48(4): 447-455

15. Larroza A, Moratal D, Paredes-Sánchez A, Soria-Olivas E, Chust ML, Arribas LA, Arana E (2015) Support vector machine classification of brain metastasis and radiation necrosis based on texture analysis in MRI. J Magn Reson Imaging 42(5): $1362-1368$

16. Oppedal K, Eftestøl T, Engan K, Beyer MK, Aarsland D (2015) Classifying dementia using local binary patterns from different regions in magnetic resonance images. Int J of Biomed Imag doi:10.1155/2015/572567

17. Nanni L, Lumini A, Brahnam S (2010) Local binary patterns variants as texture descriptors for medical image analysis. Artif Intell Med 49(2): 117-25

18. Ojala T, Pietikainen M, Maenpaa T (2002) Multiresolution gray-scale and rotation invariant texture classification with local binary patterns. IEEE Trans Pattern Anal Mach Intell 24(7): 971-987

19. Guo Z H, Zhang L, Zhang D (2010) Rotation invariant texture classification using LBP variance (LBPV) with global matching. Pattern Recognit 43(3): 706-719 
20. Mouthuy N, Cosnard G, Abarca-Quinones J, Michoux N (2012) Multiparametric magnetic resonance imaging to differentiate high-grade gliomas and brain metastases. J Neuroradiol 39(5): 301-307

21. Chernov MF, Hayashi M, Izawa M, Ono Y, Hori T (2006) Proton magnetic resonance spectroscopy (MRS) of metastatic brain tumors: variations of metabolic profile. Int J Clin Oncol 11(5): 375-84

22. Orlhac F, Soussan M, Chouahnia K, Martinod E, Buvat I (2015) 18F-FDG PETderived textural indices reflect tissue-specific uptake pattern in non-small cell lung cancer PLoS One doi:10.1371/journal.pone.0145063

23. Mahmoud-Ghoneim D, Alkaabi MK, De Certaines JD, Goettsche F-M (2008) The impact of image dynamic range on texture classification of brain white matter. BMC Med Imaging 8:18

24. Fetit AE, Novak J, Peet AC, Arvanitis TN (2015) Three-dimensional textural features of conventional MRI improve diagnostic classification of childhood brain tumours. NMR Biomed 28(9): 1174-1184

25. Depeursinge A, Foncubierta-Rodriguez A, Van De Ville D, Müller H (2014) Three-dimensional solid texture analysis in biomedical imaging: Review and opportunities. Med Image Anal 18(1): 176-196

26. Suoranta S, Holli-Helenius K, Koskenkorva P, Niskanen E, Könönen M, Äikiä M, Eskola H, Kälviäinen R,Vanninen R (2013) 3D Texture Analysis Reveals Imperceptible MRI Textural Alterations in the Thalamus and Putamen in Progressive Myoclonic Epilepsy Type 1, EPM1. PLoS One doi: 10.1371/journal.pone.0069905 
27. Allin Christe S, Vasantha Kumari B, Kandaswamy A (2012) Experimental study for 3D statistical property based intracranial brain tumor classification. J Sci Ind Res 71(1): 36-44

28. Dietrich O, Raya JG, Reeder SB, Reiser MF, Schoenberg SO (2007) Measurement of signal-to-noise ratios in MR images: Influence of multichannel coils, parallel imaging, and reconstruction filters. J Magn Reson Imaging 26(2): 375-385

29. Li Z, Mao Y, Li H, Yu G, Wan H, Li B (2016) Differentiating brain metastases from different pathological types of lung cancers using texture analysis of $\mathrm{T} 1$ postcontrast MR. Magn Reson Med 76(5): 1410-1419

30. Sassi O Ben, Sellami L, Slima M Ben, Chtourou K, Hamida A Ben (2013) Improved spatial gray level dependence matrices for texture analysis. Int J Comput Sci Inf Technol 4(6): 209

31. Carl Philips and Daniel Li (2008) Matlab function - cooc3d.m, available at https://www.mathworks.com/matlabcentral/fileexchange/19058-cooc3d

32. Ganeshan B, Miles KA, Young RC, Chatwin CR (2007) Hepatic entropy and uniformity: additional parameters that can potentially increase the effectiveness of contrast enhancement during abdominal CT. Clin Radiol 62(8): 761-768

33. Wibmer A, Hricak H, Gondo T, Matsumoto K, Veeraraghavan H, Fehr D, Zheng J, Goldman D, Moskowitz C, Fine SW, Reuter VE, Eastham J, Sala E, Vargas HA (2015) Haralick texture analysis of prostate MRI: utility for differentiating noncancerous prostate from prostate cancer and differentiating prostate cancers with different Gleason scores. Eur Radiol 25(10): 2840-2850 
34. Molina D, Pérez-Beteta J, Martínez-González A, Martino J, Velásquez C, Arana E, Pérez-García VM (2016) Influence of gray level and space discretization on brain tumor heterogeneity measures obtained from magnetic resonance images. Comput Biol Med 78: 49-57

35. Yang D, Rao G, Martinez J, Veeraraghavan A, Rao A (2015) Evaluation of tumorderived MRI-texture features for discrimination of molecular subtypes and prediction of 12-month survival status in glioblastoma. Med Phys 42(11): 67256735

36. Sikio M, Holli-Helenius KK, Ryymin P, Dastida P, Eskola H, Harrison L (2015) The effect of region of interest size on textural parameters. 2015 9th Int Symp Image Signal Process Anal IEEE 149-153

37. Brooks FJ, Grigsby PW (2014) The effect of small tumor volumes on studies of intratumoral heterogeneity of tracer uptake. J Nucl Med 55(1):37-42 


\section{Figure Captions}

Figure 1. These images show the main steps of image processing applied: unprocessed MR image (A), LBP map (B), segmented brain tumor (C), binary mask (D), area inside the mask on contrast-enhanced T1-weighted image (E), and on LBP map (F).

Figure 2. Calculated contrast, correlation, energy and homogeneity values with 2D TA on LBP maps for every ROI size combined. All differences between the two types of metastasis were statistically significant for these features ( $p<0.004$; see Table 6 for further details).

Figure 3. Contrast, correlation, energy and homogeneity for each ROI size, calculated on LBP maps with 2D TA. All differences between breast and lung metastases were statistically significant for these features $(\mathrm{p}<0.004$; see Table 6 for further details. See numbers of cases in Table 2a.)

Figure 4. ROC curves of the SDHPs from weighted 3D TA. A.- contrast (AUC $=0.694, p=$ 0.012) and entropy (AUC $=0.661, p=0.036)$, B.- correlation $(\mathrm{AUC}=0.714, \mathrm{p}=0.005)$, energy $(\mathrm{AUC}=0.706, \mathrm{p}=0.008)$, homogeneity $(\mathrm{AUC}=0.700, \mathrm{p}=0.009)$.

Figure 5. ROC curves from the true 3D TA show characteristically different balance between sensitivity and specificity for entropy $(\mathrm{AUC}=0.683, \mathrm{p}=0.017)$ and energy $(\mathrm{AUC}=0.669, \mathrm{p}=$ 0.027). 


\section{Table Titles}

Table 1. Formulas for the texture indices based on the co-occurrence matrix. $\mathrm{P}_{\mathrm{ij}}$ is the ith and jth element of the co-occurrence matrix. The $\mu_{\mathrm{i}}, \sigma_{\mathrm{i}}$, and $\mu_{\mathrm{j}}, \sigma_{\mathrm{j}}$ parameters designate the weighted mean and variance in row $i$ and column $j$ of the co-occurrence matrix, respectively. $\mathrm{N}$ is the size of the co-occurrence matrix. These features were first proposed by Haralick [12].

Table 2a. Number of tumor slices (2D ROIs) analysed, for both pathological classes and each size range.

Table $2 \mathrm{~b}$. Number of metastasis with and without necrotic lesions. In the parentheses the percentage values are also presented.

Table 3. The results of the normality tests for the four tumor size subgroups, and the image types at 2D TA (contrast-enhanced T1-weighted or derived LBP images).

Table 4. Statistically Different Heterogeneity Parameters (SDHPs) in each image type and ROI size subgroup in 2D TA

Table 5. P values of the statistical tests for each texture parameter and tumor size in case of contrast-enhanced T1-weighted images, for 2D TA.

Table 6. $\mathrm{P}$ values of the statistical tests for each texture parameter and tumor size in case of LBP maps, for 2D TA.

Table 7. SDHPs calculated from LBP maps, for 3D TA. 
TABLES

\begin{tabular}{|l|c|}
\hline Correlation & $\sum_{i, j=0}^{N-1} P_{i, j} \cdot\left[\frac{\left(i-\mu_{i}\right)\left(j-\mu_{j}\right)}{\sqrt{\left(\sigma_{i}^{2}\right)\left(\sigma_{j}^{2}\right)}}\right]$ \\
& $\mu_{i}=\sum_{i, j=0}^{N-1} i \cdot P_{i, j} \quad$ and $\mu_{j}=\sum_{i, j=0}^{N-1} j \cdot P_{i, j}$, \\
\hline Contrast & $\sigma_{i}^{2}=\sum_{i, j=0}^{N-1} P_{i, j} \cdot\left(i-\mu_{i}\right)^{2}$ and $\sigma_{j}^{2}=\sum_{i, j=0}^{N-1} P_{i, j} \cdot\left(j-\mu_{j}\right)^{2}$ \\
\hline Dissimilarity & $\sum_{i, j=0}^{N-1} P_{i, j} \cdot(i-j)^{2}$ \\
\hline Energy & $\sum_{i, j=0}^{N-1} P_{i, j} \cdot|\mathrm{i}-\mathrm{j}|$ \\
\hline Entropy & $\sum_{i, j=0}^{N-1} P_{i, j}^{2}$ \\
\hline Homogeneity & $\sum_{i, j=0}^{N-1} P_{i, j} \cdot\left(-\log P_{i, j}\right)$ \\
\hline
\end{tabular}

Table 1. Formulas for texture indices based on the co-occurrence matrix. $\mathrm{P}_{\mathrm{ij}}$ is the ith and $\mathrm{jth}$ element of the co-occurrence matrices. The $\mu_{\mathrm{i}}, \sigma_{\mathrm{i}}$, and $\mu_{\mathrm{j}}, \sigma_{\mathrm{j}}$ parameters designate the weighted mean and variance in row $\mathrm{i}$ and column $\mathrm{j}$ of the co-occurrence matrix, respectively. $\mathrm{N}$ is the size of the co-occurrence matrix. These features were first proposed by Haralick [12]. 


\begin{tabular}{|c|c|c|}
\hline ROI size $\left[\mathrm{mm}^{2}\right]$ & $\begin{array}{c}\text { Metastasis from breast } \\
\mathrm{N}_{\text {breast }}\end{array}$ & $\begin{array}{c}\text { Metastasis from lung } \\
\mathrm{N}_{\text {lung }}\end{array}$ \\
\hline $0-1935$ & 175 & 232 \\
\hline $1936-3845$ & 93 & 16 \\
\hline $3846-7700$ & 106 & 166 \\
\hline $7701-11540$ & 41 & 17 \\
\hline TOTAL: & 415 & 431 \\
\hline
\end{tabular}

Table 2a. Number of tumor slices (ROIs) analyzed, for both pathological classes, and each size range.

\begin{tabular}{|c|c|c|}
\hline Metastasis & Necrosis & No necrosis \\
\hline from breast & $18(69.2 \%)$ & $8(30.8 \%)$ \\
\hline from lung & $30(93.8 \%)$ & $2(6.3 \%)$ \\
\hline
\end{tabular}

Table $2 \mathrm{~b}$. Number of metastasis with and without necrotic lesions. In parentheses the percentage values are also presented.

\begin{tabular}{|c|c|c|c|c|c|c|c|c|c|c|c|c|c|}
\hline & & \multicolumn{7}{|c|}{ Histogram-based parameters } & \multicolumn{5}{|c|}{$\begin{array}{l}\text { Co-occurrence matrix derived } \\
\text { parameters }\end{array}$} \\
\hline & 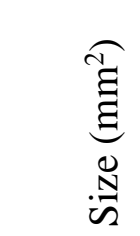 & .尹 & 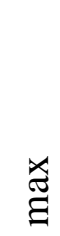 & 苂 & ڤి & 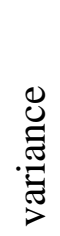 & 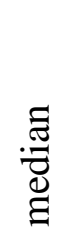 & 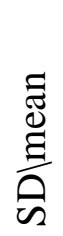 & $\begin{array}{l}\overrightarrow{\tilde{3}} \\
\stackrel{\Xi}{0} \\
\overrightarrow{0}\end{array}$ & 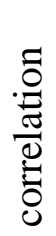 & $\begin{array}{l}\text { क्d } \\
\overrightarrow{0} \\
\vec{d}\end{array}$ & 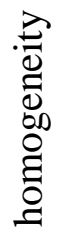 & 突 \\
\hline \multirow{4}{*}{ E } & $0-1935$ & $\mathrm{t}$ & $\begin{array}{l}\mathrm{M}- \\
\mathrm{W}\end{array}$ & $\begin{array}{l}\mathrm{M}- \\
\mathrm{W}\end{array}$ & $\begin{array}{l}\text { M- } \\
\text { W }\end{array}$ & $\begin{array}{l}\text { M- } \\
\text { W }\end{array}$ & $\begin{array}{l}\text { M- } \\
\text { W }\end{array}$ & $\mathrm{t}$ & $\begin{array}{l}\mathrm{M}- \\
\mathrm{W}\end{array}$ & $\mathrm{t}$ & $\mathrm{t}$ & $\mathrm{t}$ & $\mathrm{t}$ \\
\hline & $\begin{array}{l}1936- \\
3845\end{array}$ & $\begin{array}{l}\text { M- } \\
\text { W }\end{array}$ & $\begin{array}{l}\mathrm{M}- \\
\mathrm{W}\end{array}$ & $\begin{array}{l}\mathrm{M}- \\
\mathrm{W}\end{array}$ & $\begin{array}{l}\text { M- } \\
\mathrm{W}\end{array}$ & $\begin{array}{l}\mathrm{M}- \\
\mathrm{W}\end{array}$ & $\begin{array}{l}\text { M- } \\
\text { W }\end{array}$ & $\mathrm{t}$ & $\begin{array}{l}\mathrm{M}- \\
\mathrm{W}\end{array}$ & $\begin{array}{l}\mathrm{M}- \\
\mathrm{W}\end{array}$ & $\begin{array}{l}\text { M- } \\
\text { W }\end{array}$ & $\begin{array}{l}\mathrm{M}- \\
\mathrm{W}\end{array}$ & $\begin{array}{l}\mathrm{M}- \\
\mathrm{W}\end{array}$ \\
\hline & $\begin{array}{l}3846- \\
7700\end{array}$ & $\begin{array}{l}\text { M- } \\
\mathrm{W}\end{array}$ & $\begin{array}{l}\mathrm{M}- \\
\mathrm{W}\end{array}$ & $\begin{array}{l}\mathrm{M}- \\
\mathrm{W}\end{array}$ & $\begin{array}{l}\text { M- } \\
\mathrm{W}\end{array}$ & $\begin{array}{l}\text { M- } \\
\mathrm{W}\end{array}$ & $\begin{array}{l}\text { M- } \\
\mathrm{W}\end{array}$ & $\begin{array}{l}\text { M- } \\
\mathrm{W}\end{array}$ & $\begin{array}{l}\text { M- } \\
\mathrm{W}\end{array}$ & $\mathrm{t}$ & $\mathrm{t}$ & $\begin{array}{l}\mathrm{M}- \\
\mathrm{W}\end{array}$ & $\mathrm{t}$ \\
\hline & $\begin{array}{l}7701- \\
11540\end{array}$ & $\begin{array}{l}\text { M- } \\
\text { W }\end{array}$ & $\begin{array}{l}\text { M- } \\
\text { W }\end{array}$ & $\begin{array}{l}\mathrm{M}- \\
\mathrm{W}\end{array}$ & $\mathrm{t}$ & $\mathrm{t}$ & $\begin{array}{l}\text { M- } \\
\text { W }\end{array}$ & $\begin{array}{l}\text { M- } \\
\text { W }\end{array}$ & $\mathrm{t}$ & $\begin{array}{l}\text { M- } \\
\text { W }\end{array}$ & $\begin{array}{l}\text { M- } \\
\text { W }\end{array}$ & $\begin{array}{l}\text { M- } \\
\text { W }\end{array}$ & $\mathrm{t}$ \\
\hline \multirow{4}{*}{$\stackrel{\vartheta}{a}$} & $0-1935$ & $\mathrm{t}$ & $\mathrm{t}$ & $\mathrm{t}$ & $\begin{array}{l}\text { M- } \\
\text { W }\end{array}$ & $\begin{array}{l}\text { M- } \\
\text { W }\end{array}$ & $\mathrm{t}$ & $\mathrm{t}$ & $\begin{array}{l}\text { M- } \\
\text { W }\end{array}$ & $\begin{array}{l}\text { M- } \\
\text { W }\end{array}$ & $\begin{array}{l}\text { M- } \\
\text { W }\end{array}$ & $\begin{array}{l}\text { M- } \\
\text { W }\end{array}$ & $\mathrm{t}$ \\
\hline & $\begin{array}{l}1936- \\
3845\end{array}$ & $\mathrm{t}$ & $\mathrm{t}$ & $\begin{array}{l}\mathrm{M}- \\
\mathrm{W}\end{array}$ & $\begin{array}{l}\mathrm{M}- \\
\mathrm{W}\end{array}$ & $\begin{array}{l}\text { M- } \\
\text { W }\end{array}$ & $\begin{array}{l}\text { M- } \\
\text { W }\end{array}$ & $\begin{array}{l}\text { M- } \\
\text { W }\end{array}$ & $\begin{array}{l}\text { M- } \\
\text { W }\end{array}$ & $\begin{array}{l}\text { M- } \\
\text { W }\end{array}$ & $\begin{array}{l}\text { M- } \\
\text { W }\end{array}$ & $\begin{array}{l}\text { M- } \\
\text { W }\end{array}$ & $\begin{array}{l}\text { M- } \\
\text { W }\end{array}$ \\
\hline & $\begin{array}{l}3846- \\
7700\end{array}$ & $\mathrm{t}$ & $\mathrm{t}$ & $\begin{array}{l}\text { M- } \\
\text { W }\end{array}$ & $\begin{array}{l}\text { M- } \\
\text { W }\end{array}$ & $\begin{array}{l}\text { M- } \\
\text { W }\end{array}$ & $\begin{array}{l}\text { M- } \\
\text { W }\end{array}$ & $\begin{array}{l}\text { M- } \\
\text { W }\end{array}$ & $\begin{array}{l}\text { M- } \\
\text { W }\end{array}$ & $\begin{array}{l}\text { M- } \\
\text { W }\end{array}$ & $\begin{array}{l}\text { M- } \\
\text { W }\end{array}$ & $\begin{array}{l}\text { M- } \\
\text { W }\end{array}$ & $\begin{array}{l}\text { M- } \\
\text { W }\end{array}$ \\
\hline & $\begin{array}{l}7701- \\
11540\end{array}$ & $\mathrm{t}$ & $\mathrm{t}$ & $\mathrm{t}$ & $\begin{array}{l}\text { M- } \\
\text { W }\end{array}$ & $\begin{array}{l}\text { M- } \\
\text { W }\end{array}$ & $\mathrm{t}$ & $\mathrm{t}$ & $\begin{array}{l}\text { M- } \\
\text { W }\end{array}$ & $\begin{array}{l}\text { M- } \\
\text { W }\end{array}$ & $\begin{array}{l}\text { M- } \\
\text { W }\end{array}$ & $\begin{array}{l}\text { M- } \\
\text { W }\end{array}$ & $\begin{array}{l}\text { M- } \\
\text { W }\end{array}$ \\
\hline
\end{tabular}

t: t-test (grayed out); M-W: Mann-Whitney test 
Table 3. The results of the normality tests for the four tumor size subgroups and the image types (contrast-enhanced T1-weighted or derived LBP image).

\begin{tabular}{|c|c|c|}
\hline ROI size $\left[\mathrm{mm}^{2}\right]$ & CET1 & LBP \\
\hline $0-1935$ & 0 & 4 \\
\hline $1936-3845$ & 9 & 8 \\
\hline $3846-7700$ & 6 & 9 \\
\hline $7701-11540$ & 3 & 7 \\
\hline
\end{tabular}

Table 4. Statistically Different Heterogeneity Parameters (SDHPs) in each image type and ROI size subgroup

\begin{tabular}{|c|c|c|c|c|c|c|c|c|c|c|c|c|}
\hline \multirow{2}{*}{$\begin{array}{l}\begin{array}{l}\text { ROI size } \\
\text { [mm2] }\end{array} \\
\text { Contrast- } \\
\text { enhanced } \\
\text { T1- } \\
\text { weighted }\end{array}$} & \multicolumn{7}{|c|}{ Histogram-based parameters } & \multicolumn{5}{|c|}{$\begin{array}{c}\text { Co-occurrence matrix derived } \\
\text { parameters }\end{array}$} \\
\hline & $\overline{\mathrm{MIN}}$ & $\overline{\mathrm{MAX}}$ & MEAN & 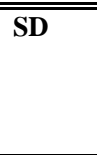 & 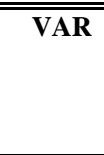 & MEDIAN & $\begin{array}{c}\text { SD/ } \\
\text { MEAN }\end{array}$ & $\overline{\text { CONT }}$ & 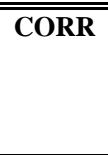 & 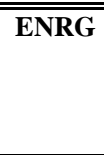 & 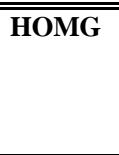 & ENTR \\
\hline $\begin{array}{l}0- \\
1935\end{array}$ & .979 & .054 & .017 & .062 & .062 & .013 & .054 & .191 & .493 & .658 & .051 & .305 \\
\hline $\begin{array}{l}\text { 1936- } \\
3845\end{array}$ & .001 & .001 & .039 & .002 & .002 & .093 & .735 & .000 & .004 & .000 & .000 & .000 \\
\hline $\begin{array}{l}3846- \\
7700 \\
\end{array}$ & .002 & .000 & .029 & .000 & .000 & .177 & .000 & .002 & .973 & .420 & .053 & .286 \\
\hline $\begin{array}{l}\text { 7701- } \\
11540\end{array}$ & .002 & .814 & .138 & .045 & .308 & .087 & .000 & .569 & .001 & .287 & .035 & .064 \\
\hline
\end{tabular}

significant difference after Bonferroni correction

Table 5. $\mathrm{P}$ values of the statistical tests for each texture parameter and tumor size in case of contrast-enhanced T1-weighted images. 


\begin{tabular}{|c|c|c|c|c|c|c|c|c|c|c|c|c|}
\hline \multirow{2}{*}{$\begin{array}{l}\begin{array}{l}\text { ROI size } \\
\text { [mm2] }\end{array} \\
\text { LBP } \\
\text { maps }\end{array}$} & \multicolumn{7}{|c|}{ Histogram-based parameters } & \multicolumn{5}{|c|}{$\begin{array}{c}\text { Co-occurrence matrix derived } \\
\text { parameters }\end{array}$} \\
\hline & 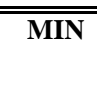 & MAX & MEAN & SD & $\overline{\text { VAR }}$ & " MEDIAN & $\begin{array}{c}\text { SD/ } \\
\text { MEAN }\end{array}$ & $\overline{\text { CONT }}$ & CORR & ENRG & HOMG & ENTR \\
\hline $\begin{array}{l}0- \\
1935\end{array}$ & n.a. & n.a & .157 & .018 & .018 & .119 & .843 & .000 & .000 & .003 & .000 & .081 \\
\hline $\begin{array}{l}\text { 1936- } \\
3845\end{array}$ & n.a & n.a & .000 & .072 & .072 & .000 & .000 & .001 & .000 & .000 & .000 & .000 \\
\hline $\begin{array}{l}3846- \\
7700 \\
\end{array}$ & n.a & n.a & .001 & .000 & .000 & .005 & .000 & .000 & .000 & .000 & .000 & .000 \\
\hline $\begin{array}{l}\text { 7701- } \\
11540\end{array}$ & n.a & n.a & .617 & .001 & .001 & .062 & .398 & .000 & .000 & .000 & .000 & .000 \\
\hline
\end{tabular}

significant difference after Bonferroni correction

n.a - not applicable

Table 6. $\mathrm{P}$ values of the statistical tests for each texture parameter and tumor size in case of LBP maps.

\begin{tabular}{|c|c|c|c|c|c|c|c|}
\hline \multirow{3}{*}{$\begin{array}{l}\text { Statistical } \\
\text { test }\end{array}$} & \multicolumn{7}{|c|}{ LBP images } \\
\hline & \multicolumn{5}{|c|}{ weighted 3D } & \multicolumn{2}{|c|}{ true $3 \mathrm{D}$} \\
\hline & Contrast & Correlation & Energy & Homogeneity & Entropy & Energy & Entropy \\
\hline $\begin{array}{l}\text { Kolmogorov- } \\
\text { Smirnov }\end{array}$ & $\begin{array}{l}.116 \\
.200\end{array}$ & $\begin{array}{l}.004 \\
.200\end{array}$ & $\begin{array}{l}.000 \\
.037\end{array}$ & $\begin{array}{l}.034 \\
.200\end{array}$ & $\begin{array}{l}.031 \\
.200\end{array}$ & $\begin{array}{l}.000 \\
.037\end{array}$ & $\begin{array}{l}.000 \\
.039\end{array}$ \\
\hline $\begin{array}{l}\text { Mann- } \\
\text { Whitney U } \\
\text { or } \\
\text { T Test }\end{array}$ & $\begin{array}{c}\mathrm{T} \\
.036\end{array}$ & $\begin{array}{l}\text { MW } \\
.005\end{array}$ & $\begin{array}{l}\text { MW } \\
.008\end{array}$ & $\begin{array}{l}\text { MW } \\
.009\end{array}$ & $\begin{array}{l}\text { MW } \\
.036\end{array}$ & $\begin{array}{l}\text { MW } \\
.027\end{array}$ & $\begin{array}{l}\text { MW } \\
.017\end{array}$ \\
\hline
\end{tabular}

Table 7. P values of the statistical tests for the 3D texture analysis of LBP maps. T: t-test; MW: Mann-Whitney test 


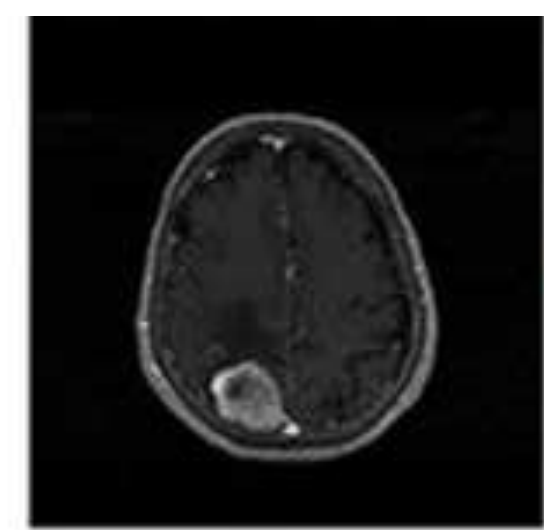

A
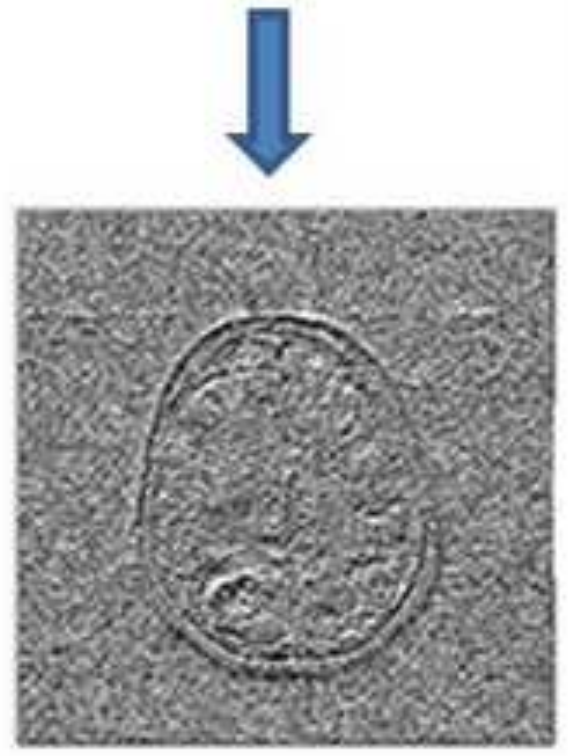

B
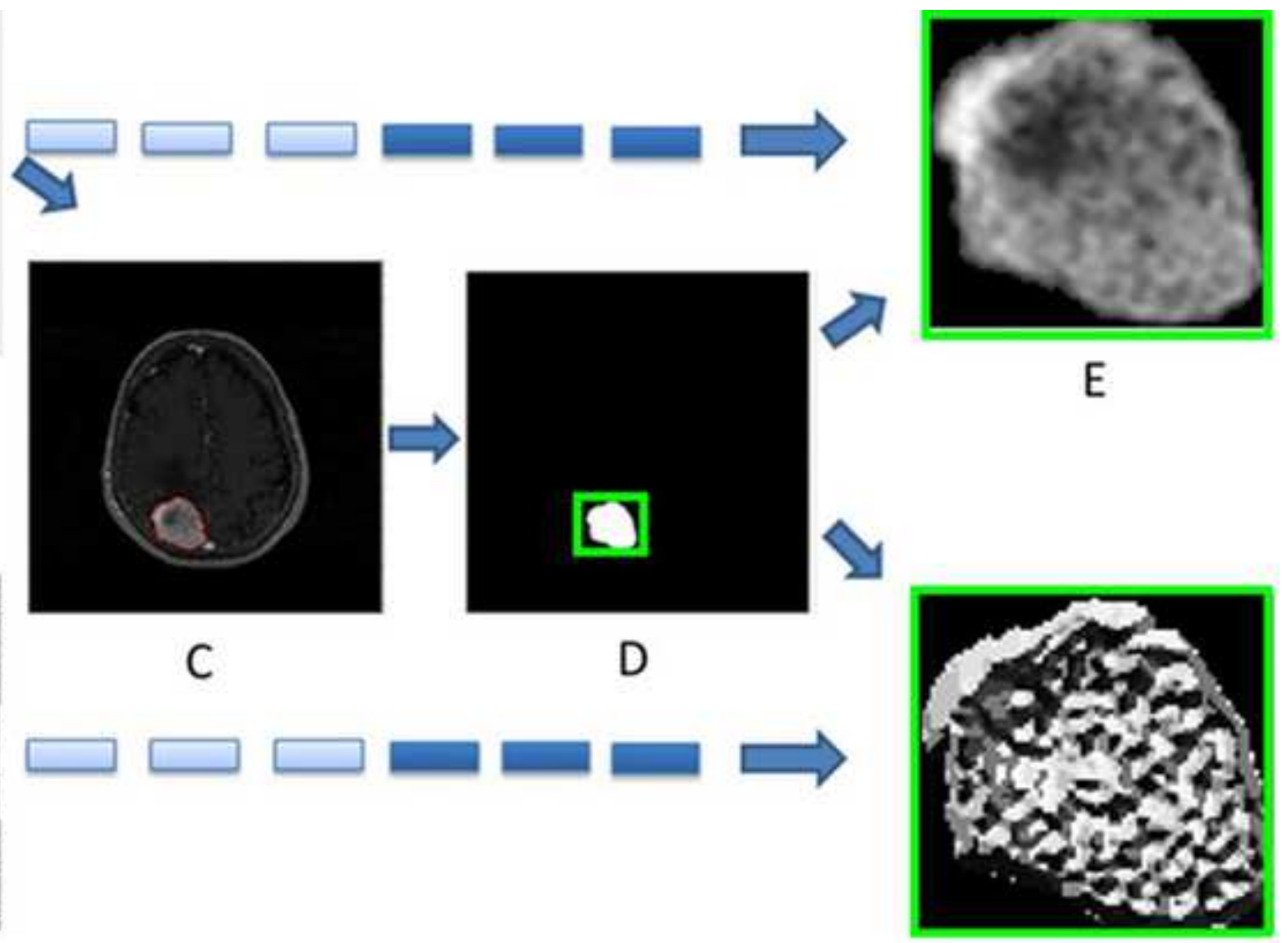

F 
Click here to download Figure figure_2.jpg $\underline{\underline{\Perp}}$
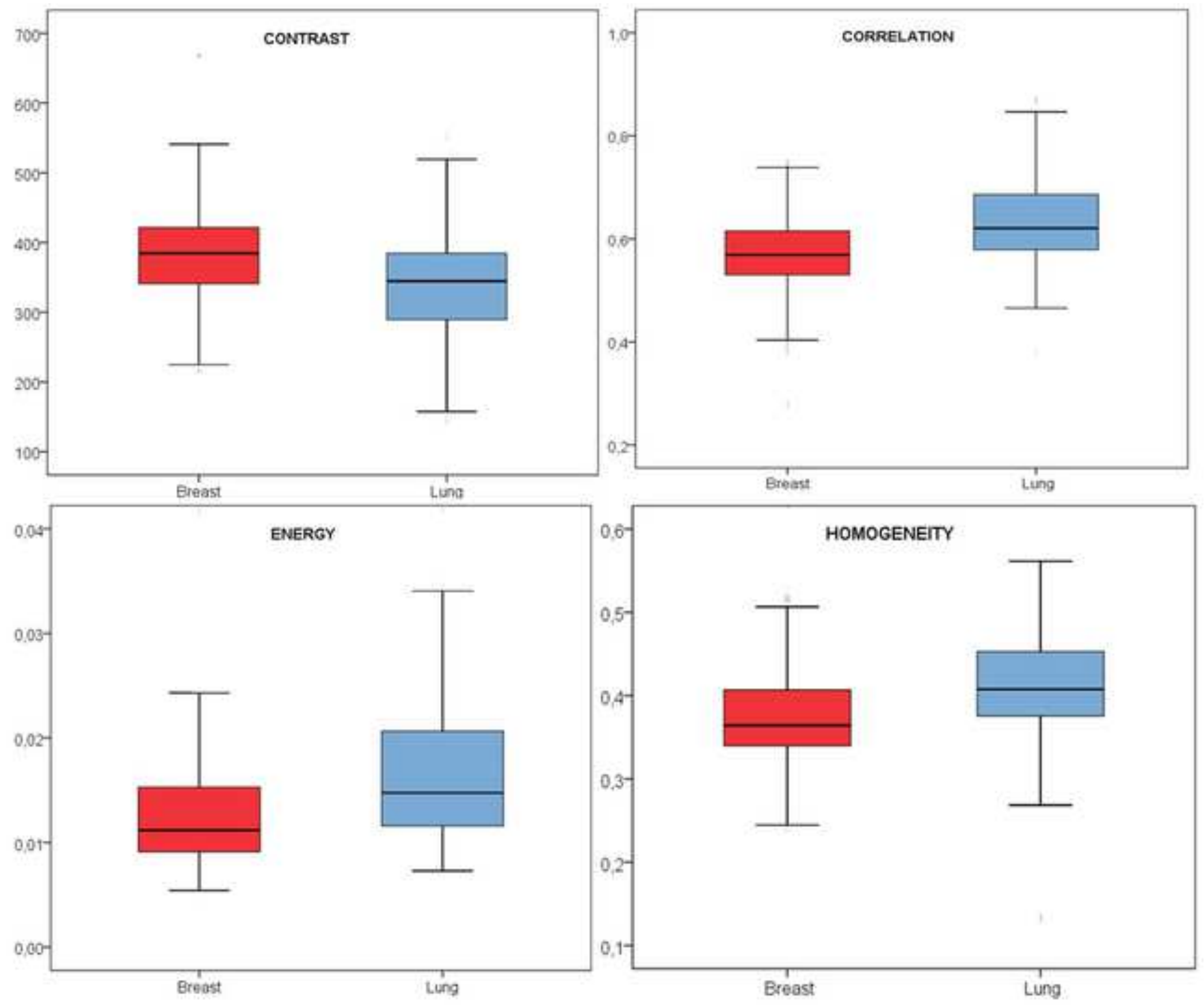

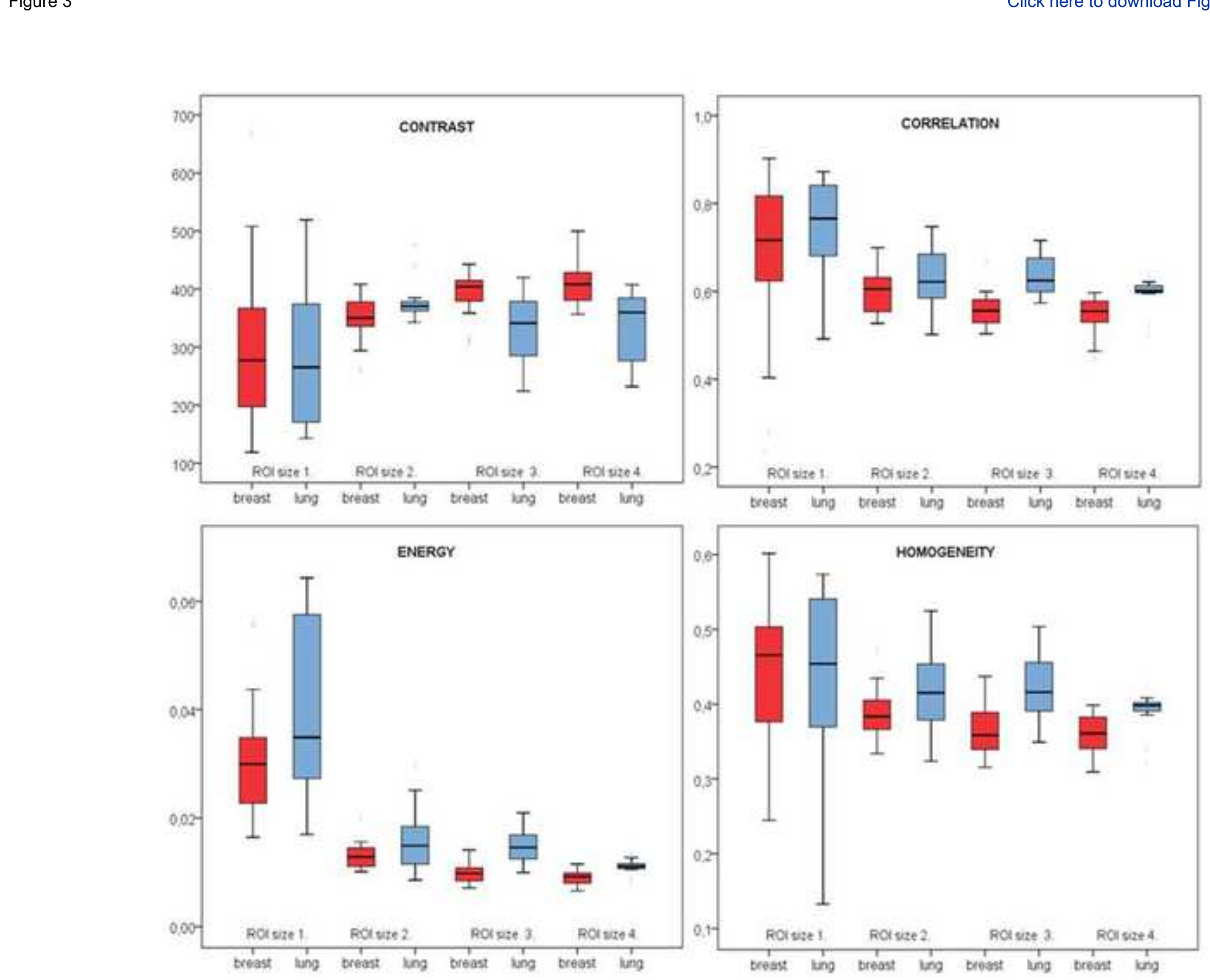


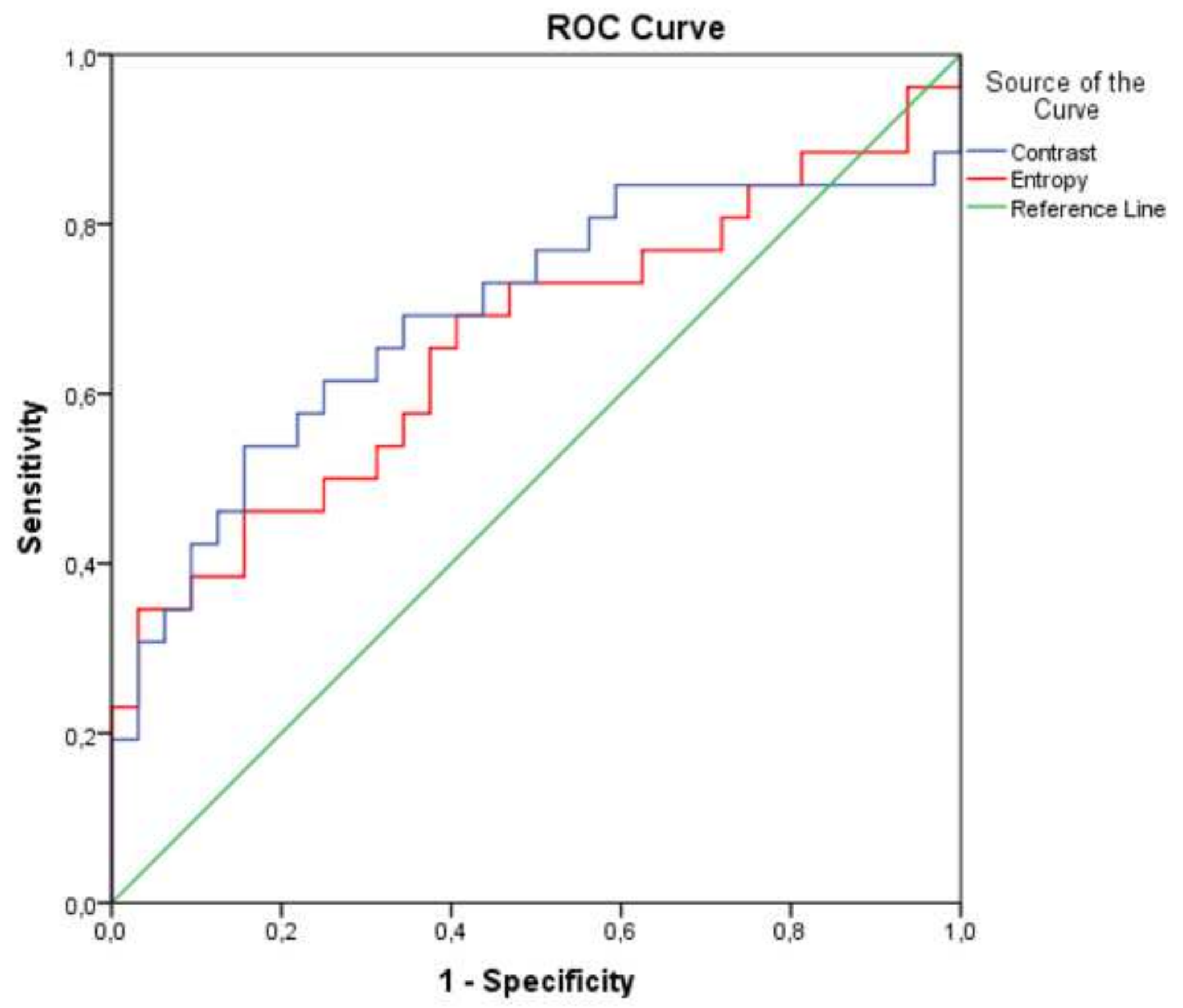




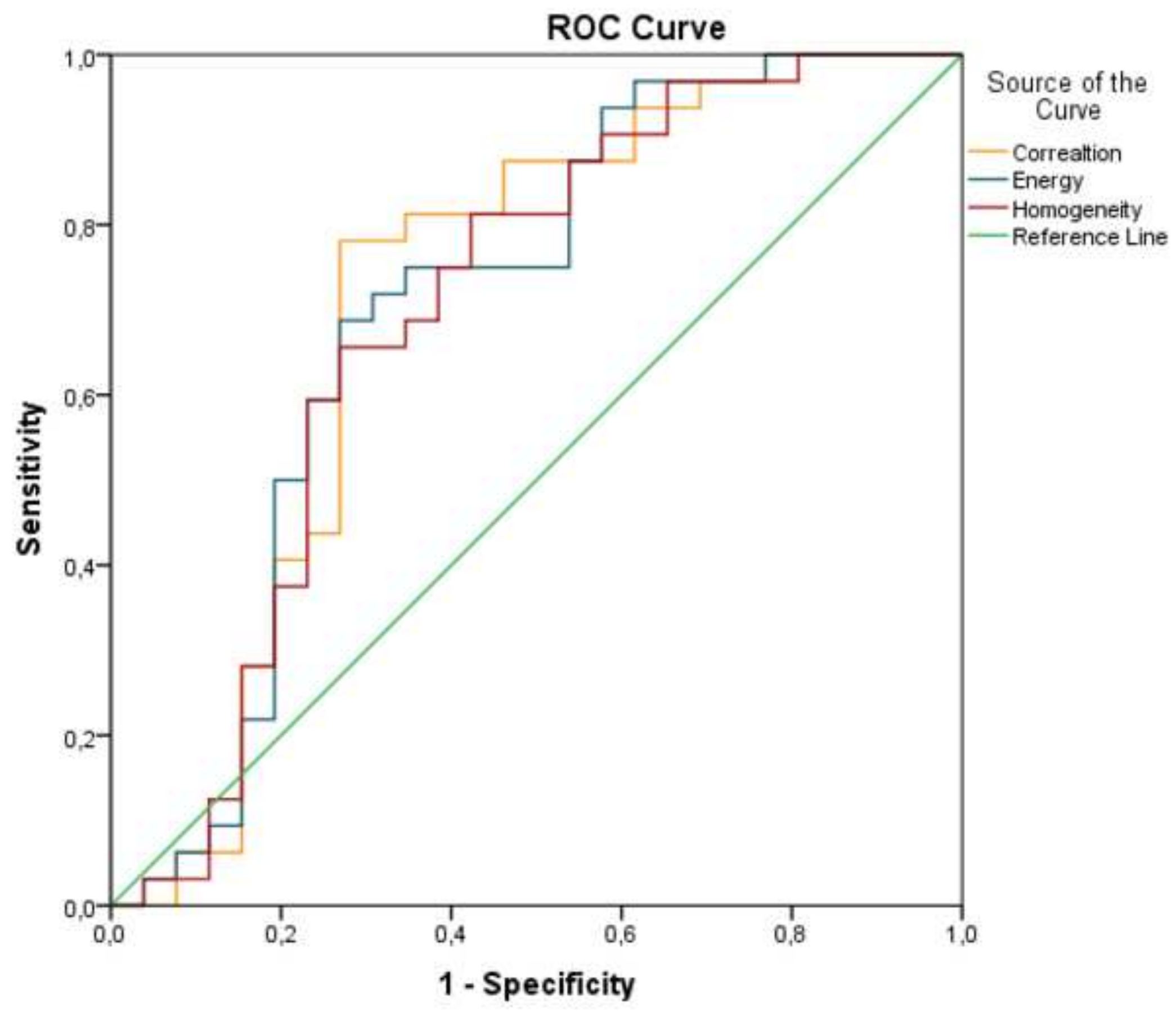




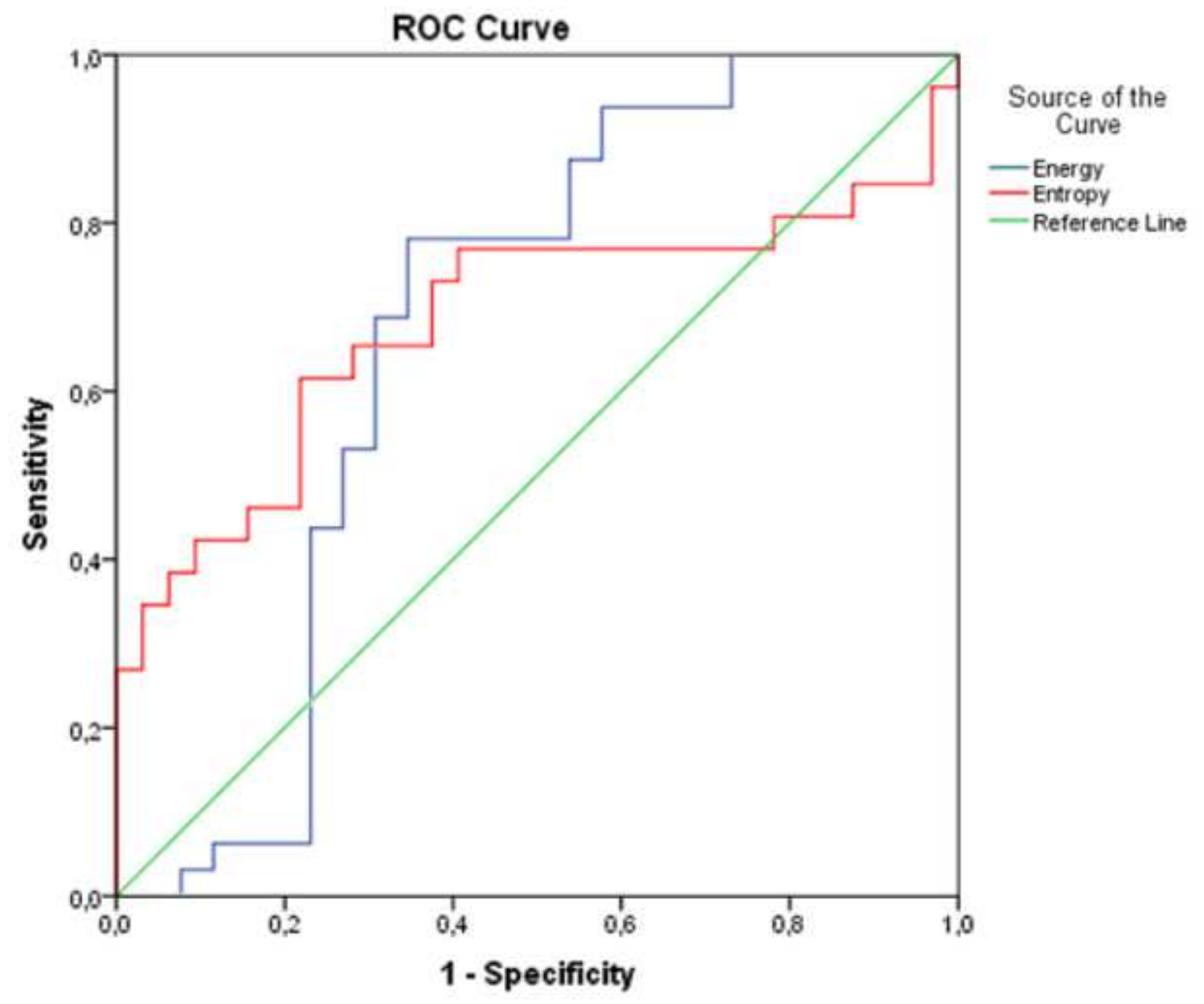

